Regular Article

\title{
Green multi-functional monomer based ion imprinted polymers for selective removal of copper ions from aqueous solution
}

\author{
Liyan Wang a,b,c , Jinhua Li ${ }^{\text {a }}$, Jianan Wang ${ }^{\mathrm{e}}$, Xiaotong Guo ${ }^{\mathrm{a}, \mathrm{b}}$, Xiaoyan Wang ${ }^{\mathrm{a}}$, Jaebum Choo ${ }^{\mathrm{d}, *}$, \\ Lingxin Chen ${ }^{\mathrm{a}, *}$ \\ ${ }^{a}$ CAS Key Laboratory of Coastal Environmental Processes and Ecological Remediation, Research Center for Coastal Environmental Engineering and Technology, Yantai Institute \\ of Coastal Zone Research, Chinese Academy of Sciences, Yantai 264003, China \\ ${ }^{\mathrm{b}}$ University of Chinese Academy of Sciences, Beijing 100049, China \\ ${ }^{\mathrm{c}}$ Department of Polymer Chemistry, Yantai Engineering \& Technology College, Yantai 264006, China \\ ${ }^{d}$ Department of Chemistry, Chung-Ang University, Seoul 06974, South Korea \\ e School of Civil Engineering, Yantai University, Yantai 264005, China
}

\section{G R A P H I C A L A B S T R A C T}

G-HQ-C IIPs

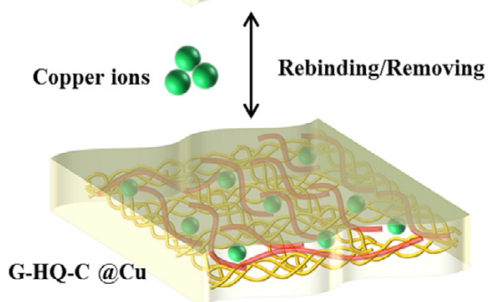

\section{A R T I C L E I N F O}

\section{Article history:}

Received 24 October 2018

Revised 19 January 2019

Accepted 21 January 2019

Available online 22 January 2019

\section{Keywords:}

Ion imprinted polymers

Multi-functional monomer imprinting

$\mathrm{Cu}(\mathrm{II})$ removal

Aqueous solution

Green synthesis

\begin{abstract}
A B S T R A C T
Green ion imprinted polymers (IIPs) were prepared in aqueous phase via the synergy of three functional monomers of low-cost eco-friendly gelatin $(G)$, 8-hydroxyquinoline (HQ) and chitosan (C), namely G-HQ$\mathrm{C}$ IIPs, and were applied as an effective and recyclable adsorbent to remove $\mathrm{Cu}(\mathrm{II})$ from aqueous solution. The as-prepared G-HQ-C IIPs were systematically characterized, and several major factors affecting adsorption capacity including solution $\mathrm{pH}$, temperature and contact time were investigated in detail. The adsorption of $\mathrm{Cu}$ (II) on G-HQ-C IIPs followed the pseudo-second-order kinetic and Langmuir isotherm models, and the adsorption capacity increased with temperature increase. Moreover, the maximum adsorption capacities of G-HQ-C IIPs toward $\mathrm{Cu}(\mathrm{II})$ reached up to $111.81 \mathrm{mg} / \mathrm{g}$ at room temperature, much higher than those of most of the reported adsorbents for $\mathrm{Cu}(\mathrm{II})$. The G-HQ-C IIPs displayed excellent selectivity against seven common divalent ions with selectivity coefficients above 18.71 as well as high anti-interference ability. Additionally, a good reusability was demonstrated without significant loss in adsorption capacity after at least ten cycles. The IIPs were applied to environmental water samples for selective removal of $\mathrm{Cu}$ (II) with satisfactory results. By replacing $\mathrm{Cu}(\mathrm{II})$ template by $\mathrm{Cd}(\mathrm{II}), \mathrm{Hg}$ (II) and $\mathrm{Pb}(\mathrm{II})$, respectively, the obtained three kinds of IIPs based on G-HQ-C presented convincing
\end{abstract}

\footnotetext{
* Corresponding authors.

E-mail addresses: jbchoo@cau.ac.kr (J. Choo), lxchen@yic.ac.cn (L. Chen).
} 
imprinting properties, and therefore the work could provide a simple and general imprinting strategy toward various concerned heavy metal ions through multi-point interactions from multiple functional monomers.

(c) 2019 Elsevier Inc. All rights reserved.

\section{Introduction}

Heavy metal pollution for water resources has drawn widespread concerns for its non-biodegradability and easy bioaccumulation [1]. As a typical kind of heavy metal, copper $(\mathrm{Cu})$ in water mainly comes from industrial and agricultural wastewater, due to its wide use in mine metallurgy, machinery manufacturing, electronics, chemical engineering, medicine, fertilizer and so on. Although copper is an essential trace element for human health, excess amounts can cause mucosal irritation, stomach discomfort, neurological damage, disorder of metabolism and necrotic of liver and kidney [2]. United States Environmental Protection Agency (USEPA) has established the maximum allowable level (MAL) for copper ions $(\mathrm{Cu}(\mathrm{II}))$ in drinking water is $1.3 \mathrm{mg} / \mathrm{L}$, and World Health Organization (WHO) requires permissible limit is $2.0 \mathrm{mg} / \mathrm{L}$ [3]. Therefore, prevention of excessive release of $\mathrm{Cu}(\mathrm{II})$ and development of novel technologies for $\mathrm{Cu}(\mathrm{II})$ removal are very important for living organisms. A number of efforts have been devoted to efficiently remove $\mathrm{Cu}(\mathrm{II})$ and other heavy metal ions, including precipitation [4], ion exchange [5], membrane separation [6], reverse osmosis [7] and adsorption [8]. Among these methods, adsorption has attracted increasing interest over recent decades because of its easier operation, high efficiency, lower cost and easier recovery of adsorbent [8]. Activated carbon, clay, agricultural by-products, molecular sieve, carbon nanotube, hydrogel, hybrid polymers and many other materials have been used as adsorbents for the adsorptive-removal of $\mathrm{Cu}(\mathrm{II})$ and other heavy metal ions from aqueous solutions [9-14].

However, it is a big challenge to adsorb target metal ions in industrial/environmental water samples for complicated matrices, co-existence of other metal ions and low contents of targeted ions. Ion imprinted polymers (IIPs) fabricated by ion imprinting technology owning the tailor-made binding sites complementary with target ions can be utilized in target ions' specific recognition in the presence of other competitive ions and complicated matrices [15-23]. Up to now, various IIPs have been prepared and employed for selective recognition, separation, removal and determination of metal ions in drinking water, surface water and waste water samples [17-23]. For example, Chen's group [2,17-19] has prepared several kinds of IIPs for selective preconcentration and detection of metal ions from water samples. Tang's group [20-22] has synthesized highly ordered ion imprinted mesoporous SBA-15 and MCM-41 organosilicas for the removal of metal ions in wastewaters. Afkhami et al. have fabricated an imprinted polymer nano-modifier for the selective and sensitive electrochemical determination of trace mercury ions in real water samples [23].

As an important branch of molecularly imprinted polymers (MIPs), IIPs need three steps for preparation which are similar to the preparation process of MIPs [15,24-27]: (1) Form complexes or composites based on chelation and electrostatic interaction between target ions (as template) and functional monomers; (2) Add cross-linkers to undertake polymerization around the complexes or composites; (3) Remove template ions to get selective recognition sites matching the template ions in size, charge, coordination number and geometry. Functional monomer offering coordination and/or electrostatic interaction to metal ions is critical to IIPs, and single functional monomer is generally used including acrylamide (AAm), acrylic acid, methacrylic acid (MAA), vinyl pyridines (VP), methacrylates, oxysilanes, etc. [28]. However, these common functional monomers usually result in low selectivity. As is well known, the recognition between templates and IIPs/MIPs can be enhanced by multi-point interactions for two/multiple functional monomers complementary to each other [19,23]. For instances, Hoai et al. [29] and Chen et al. [19] prepared $\mathrm{Cu}(\mathrm{II})$ and $\mathrm{Pb}(\mathrm{II})$ IIPs using dual functional monomers of MAA and VP by suspension polymerization, respectively. Haruki et al. [30] prepared native lysozyme MIPs to achieve high refolding yield by using AAm, MAA and 2-(dimethylamino)ethyl methacrylate as functional monomers. Inspired by these reports, we expect to fabricate a novel IIPs for highly selective recognition and removal of metal ions based on multi-point interactions from multiple functional monomers.

Recently, low cost and environmentally friendly polymers based on green chemistry principle have achieved encouraging achievements in water purification, and those containing a high content of amino, hydroxyl, carboxyl, thiol, quinoline and imidazole groups have been found to be effective to combine with metal ions [14,31-33]. Gelatin (G) obtained from skin contains rich amino, amide and carboxyl groups along the polypeptide chain or in the side chain, so it can form complex with heavy metal ions [34]. 8-Hydroxyquinoline (HQ) is a bidentate chelating agent to combine with metal ions [35]. Chitosan (C) is a potential bioadsorbent for the removal of heavy metals due to its terminal amino groups [31,36]. However, single G or C shows low adsorption capacity and selectivity towards heavy metal ions in aqueous solutions, along with poor rigidity [33]. Therefore, it is an interesting attempt to develop a novel hybrid polymer using G, HQ and C as functional monomers to improve adsorption and mechanical behavior because hybrid polymers usually show better performance than its single constituents [36-39].

Therefore, herein, green multi-functional ion imprinted polymers namely G-HQ-C IIPs were prepared by using G, HQ and C as functional monomers for selective removal of $\mathrm{Cu}$ (II) ions from aqueous solution. The polymers were fabricated by a simple chemical cross-linking method because the three monomers contain abundant amino, amide, hydroxyl, quinoline and carboxyl groups, which could crosslink with each other and chelate $\mathrm{Cu}(\mathrm{II})$ ions. Subsequently, the morphology and structure of G-HQ-C IIPs were well characterized and adsorption performances were systematically investigated. Then, the IIPs were successfully applied to environmental water samples for selective removal of $\mathrm{Cu}(\mathrm{II})$. Furthermore, other heavy metal ions of $\mathrm{Cd}(\mathrm{II}), \mathrm{Hg}(\mathrm{II})$ and $\mathrm{Pb}(\mathrm{II})$ were also used as template ions for the G-HQ-C based IIPs preparation and related results supplied convincing support for the simple and universal multi-functional monomer imprinting strategy.

\section{Experimental}

\subsection{Reagents and materials}

Gelatin (G), chitosan (C), 8-hydroxyquinoline (HQ) and glutaraldehyde were purchased from Aladdin Chemical Reagent Co., Ltd. (Shanghai, China). Other reagents and materials such as acetic acid, ethanol, formaldehyde ( $30 \%, \mathrm{w} / \mathrm{v}$ ), $\mathrm{HCl}, \mathrm{NaOH}, \mathrm{Cu}\left(\mathrm{NO}_{3}\right)_{2} \cdot 3 \mathrm{H}_{2} \mathrm{O}$, $\mathrm{CdCl}_{2} \cdot 2.5 \mathrm{H}_{2} \mathrm{O}, \mathrm{HgCl}_{2}, \mathrm{~Pb}\left(\mathrm{NO}_{3}\right)_{2}$ were supplied by the Sinopharm 
Chemical Reagent Co., Ltd. (Shanghai, China). All the reagents and materials were of at least analytical pure grade. Deionized ultrapure water with the specific resistance of $18.2 \mathrm{M} \Omega \mathrm{cm}$ was purified by Pall cascada ${ }^{\mathrm{TM}}$ lab water purification system (Pall Corp., USA) for all aqueous solution preparation throughout this work.

Lake, river and sea water samples were collected in a Teflon bottle from Sanyuan Lake located in the schoolyard of Yantai University, Guangdang River located in Laishan District and Huanghai Sea located outside the east door of Yantai University, respectively. All the water samples were stored at $4{ }^{\circ} \mathrm{C}$ in a refrigerator for use, after filtrated through $0.45 \mu \mathrm{m}$ membrane (Tianjin Jinteng Experiment Equipment Ltd., Co., Tianjin, China). Herein, real water samples were collected and filterred in accordance with the standardization process of GB 37378.3-2007 "Marine Monitoring Regulations", Part 3, "Sample Collection, Storage and Transportation". The filtration procedure aimed to remove possible microorganisms, silt soil and sand grain.

\subsection{Preparation of G-HQ-C IIPS}

The ion imprinted polymers were synthesized based on multifunctional monomer ion imprinted strategy and green chemistry principle, in which G, HQ and C were utilized as functional monomers, as schematically shown in Fig. 1.

Firstly, Mannich reaction between G and HQ occurred as illustrated in Fig. S1. In a flask connected to a reflux condenser, $4.5 \mathrm{~g}$ $\mathrm{G}$ dissolved in $75 \mathrm{~mL}$ ultrapure water was mixed with $2.25 \mathrm{~g} \mathrm{HQ}$ dissolved in $75 \mathrm{~mL}$ ethanol by stirring continuously to form a homogeneous brown solution. Then, $600 \mu \mathrm{L}$ acetic acid and $1645 \mu \mathrm{L}$ formaldehyde were added and the resulting mixture was boiled for $6 \mathrm{~h}$. Products were centrifuged, washed and dried in a vacuum oven at $60^{\circ} \mathrm{C}$ for $12 \mathrm{~h}$ to obtain gray powders named G-HQ.

Secondly, a weighed amount of G-HQ C and copper nitrate were dissolved in $0.2 \mathrm{~mol} \mathrm{~L}^{-1} \mathrm{HAc}$. The mixture were poured into a glass petri dish with a certain diameter to get uniform thickness and incubated at $60^{\circ} \mathrm{C}$ for $2 \mathrm{~h}$. Subsequently, glutaraldehyde was added for crosslinking and the membrane was further incubated at $37^{\circ} \mathrm{C}$ for $10 \mathrm{~h}$ to obtain G-HQ-C@Cu polymers.

Finally, G-HQ-C@Cu polymers were treated with $0.1 \mathrm{~mol} \mathrm{~L}^{-1}$ $\mathrm{HAc}$ to completely remove the $\mathrm{Cu}(\mathrm{II})$ ions. After neutralized by $\mathrm{NaOH}$ solution, the final products were dried in a vacuum oven at $60{ }^{\circ} \mathrm{C}$ for $12 \mathrm{~h}$. So, $\mathrm{Cu}(\mathrm{II})$ templating G-HQ-C IIPs were attained; for simplicity, G-HQ-C IIPs or IIPs were used in the following work. For comparison, non-imprinted polymers (NIPs) were also synthesized in the same manner, without the addition of copper nitrate. In addtion, the other three kinds of IIPs based on G-HQ-C were also synthesized in the same procedure by using $\mathrm{Cd}(\mathrm{II}), \mathrm{Hg}(\mathrm{II})$ and $\mathrm{Pb}(\mathrm{II})$ as template ions, respectively. Their corresponding NIPs were also prepared similarly just in the absence of template ions.

\subsection{Instrumentation}

Inductively coupled plasma mass spectrometry (ICP-MS, ELAN DRC II, PerkinElmer Ltd.) was employed to determine the concentrations of $\mathrm{Cu}(\mathrm{II})$ ions and other tested heavy metal ions. Fourier transform infrared (FT-IR) spectrometer (Thermo Nicolet Corporation, USA) was used to record the infrared spectra of samples pressed with $\mathrm{KBr}$ tablet in transmission mode. The wavenumbers of FT-IR measurement range was $600-3600 \mathrm{~cm}^{-1}$ with a resolution of $4 \mathrm{~cm}^{-1}$. Scanning electron microscope (SEM, Hitachi S-4800, Japan) was utilized to evaluate the morphological of samples sputter coated with gold at $10 \mathrm{kV}$ of accelerating voltage. 3H-2000PS1 (BET, BeiShiDe, China) type surface area analyzer was employed for Brunauer-Emmet-Teller (BET) analysis to determine the specific surface area and pore size of materials by $\mathrm{N}_{2}$ adsorptiondesorption isotherms. Malvern Zetasizer Nano-ZS90 (ZEN3590, UK) was used to measure Zeta potential.

\subsection{Adsorption experiments of G-HQ-C IIPs towards $\mathrm{Cu}(\mathrm{II})$}

Adsorption experiments were carried out by $10 \mathrm{mg}$ adsorbents and $10 \mathrm{~mL}$ solution in round bottom centrifugal tubes with a vapour-bathing vibrator at certain temperature (298, 308 and

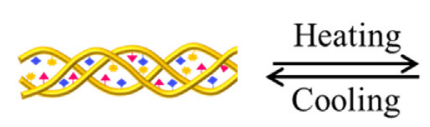

Triple helixes of gelatin

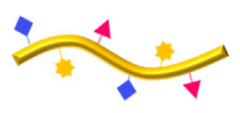

Gelatin chain

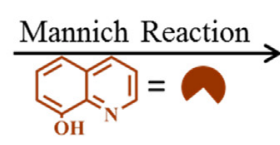

OH

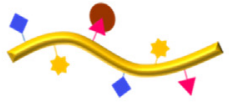

G-HQ chain

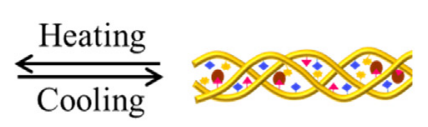

Triple helixes of G-HQ
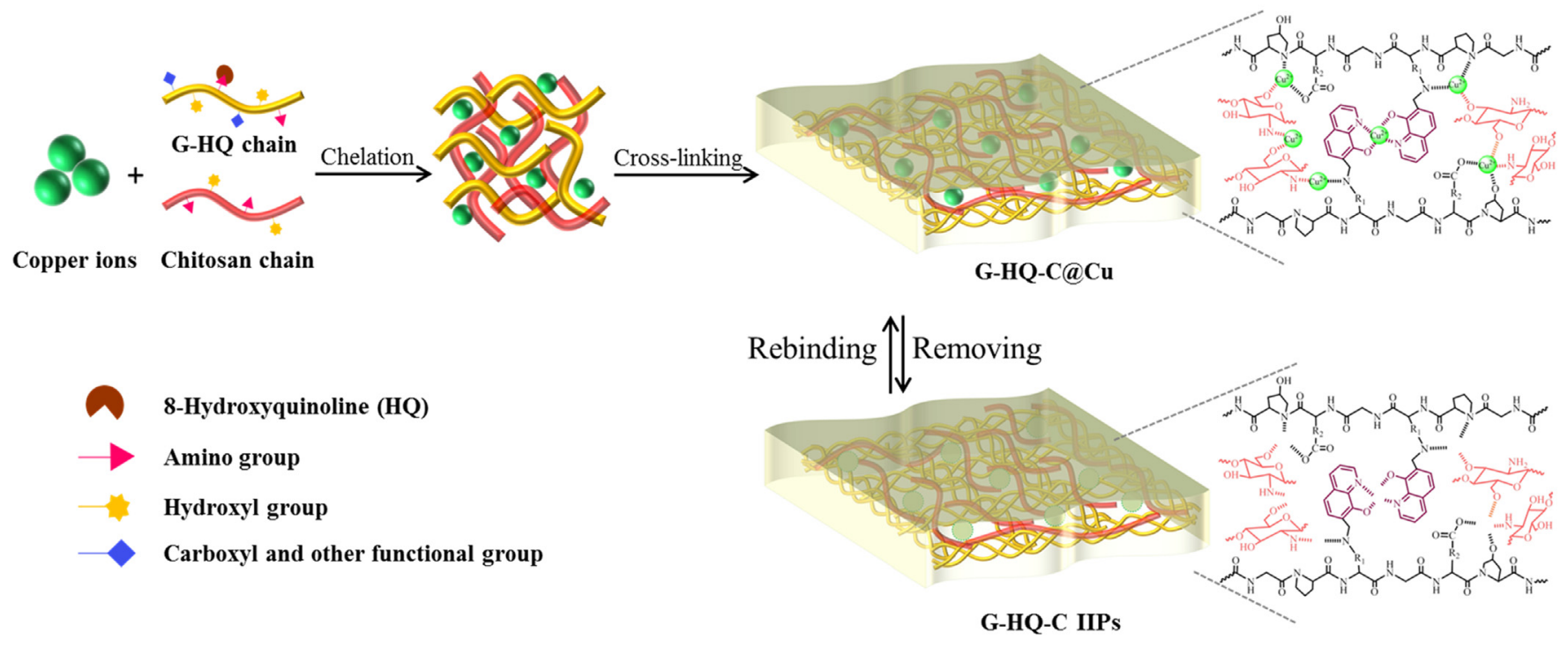

Fig. 1. Schematic illustration of the preparation process for G-HQ-C ion imprinted polymers. 
$318 \mathrm{~K}$ corresponding to 25,35 and $45^{\circ} \mathrm{C}$, respectively). All the adsorption experiments were performed in triplicate.

For the $\mathrm{pH}$ test, $10 \mathrm{mg}$ dried G-HQ-C IIPs were added to $\mathrm{Cu}(\mathrm{II})$ ions solutions $(5,100 \mathrm{mg} / \mathrm{L})$ at different $\mathrm{pH}$ values (2.0-8.0) in each tube. The initial $\mathrm{pH}$ of the solution was adjusted to 2.0-8.0 using $0.1 \mathrm{~mol} / \mathrm{L} \mathrm{HCl}$ and $0.1 \mathrm{~mol} / \mathrm{L} \mathrm{NaOH}$ solution.

For the saturated adsorption experiments, $10 \mathrm{mg}$ dried G-HQ-C IIPs/NIPs were immersed in $10 \mathrm{~mL} \mathrm{Cu(II)}$ ions solutions with desired concentrations from 5 to $500 \mathrm{mg} / \mathrm{L}$ for $24 \mathrm{~h}$ to ensure the equilibrium adsorption. The amount of $\mathrm{Cu}(\mathrm{II})$ adsorbed on G-HQC IIPs/NIPs was determined by inductively coupled plasma mass spectrometry (ICP-MS, ELAN DRC II, PerkinElmer Ltd.) based on concentration difference method. Adsorption capacity $Q_{e}(\mathrm{mg} / \mathrm{g})$ was estimated using the amount of $\mathrm{Cu}(\mathrm{II})$ ions retained on unit mass of adsorbent as the following Eq. (1):

$Q_{\mathrm{e}}=\frac{\left(C_{0}-C_{\mathrm{e}}\right) \times V}{m}$

where $Q_{\mathrm{e}}$ is adsorption capacity $(\mathrm{mg} / \mathrm{g}), C_{0}$ is the initial concentration $(\mathrm{mg} / \mathrm{L}), C_{\mathrm{e}}$ is the concentration of $\mathrm{Cu}(\mathrm{II})$ ions at equilibrium $(\mathrm{mg} / \mathrm{L}), V$ is the volume of solution(L) and $m$ is the adsorbent dose (g).

Langmuir and Freundlich adsorption isotherms models are two main models to describe the adsorption behaviours of adsorbents. Langmuir isotherm model based on the assumption that adsorption occurs at specific homogeneous adsorption sites within the adsorbent, all the adsorption sites are energetically identical and adsorption occurs on a structurally similar binding site. The Langmuir adsorption isotherm is defined as Eq. (2):

$\frac{C_{\mathrm{e}}}{Q_{\mathrm{e}}}=\frac{C_{\mathrm{e}}}{Q_{\max }}+\frac{1}{K_{\mathrm{L}} Q_{\max }}$

Freundlich isotherm model is an empirical model based on the assumption that adsorption occurs on a heterogeneous adsorbent surface in which the stronger binding sites are occupied first and that the binding strength decreases with increasing degree of site occupation. The Freundlich adsorption isotherm is defined as Eq. (3):

$\log Q_{\mathrm{e}}=\log K_{\mathrm{F}}+\frac{1}{\mathrm{n}} \log C_{\mathrm{e}}$

where $C_{\mathrm{e}}$ is the concentration of $\mathrm{Cu}(\mathrm{II})$ ions at equilibrium $(\mathrm{mg} / \mathrm{L})$; $Q_{e}$ is the amount of $\mathrm{Cu}$ (II) ions adsorbed by a unit mass of adsorbent at equilibrium (mg/g); $Q_{\max }$ is maximum adsorption capacity $(\mathrm{mg} /$ $\mathrm{g}$ ); $K_{\mathrm{L}}$ is Langmuir constant related to the heat of adsorption $(\mathrm{L} / \mathrm{mg}) ; K_{\mathrm{F}}$ and $\mathrm{n}$ are empirical constants could be obtained from slope and intercept of the plot of $\log Q_{e}-\log C_{e}$, designated as adsorption capacity and adsorption intensity, respectively.

To investigate the adsorption kinetics, $10 \mathrm{mg}$ G-HQ-C-IIPs/NIPs were added into $10 \mathrm{~mL} \mathrm{Cu(II)}$ solution with different initial concentrations $(5,30$ and $100 \mathrm{mg} / \mathrm{L}, 298 \mathrm{~K}, \mathrm{pH}=6)$ to obtain adsorption capacity $Q_{t}$ at different times. The adsorption kinetics of $\mathrm{Cu}(\mathrm{II})$ ion adsorption on G-HQ-C IIPs/NIPs were simulated with the pseudo-first order kinetics model and pseudo-second order kinetics model. The pseudo-first order kinetics model is shown in Eq. (4), while the pseudo-second order kinetics model is shown in Eq. (5):

$\log \left(Q_{\mathrm{e}}-Q_{\mathrm{t}}\right)=\log Q_{\mathrm{e}, \mathrm{c}}+\frac{k_{1}}{2.303} t$

$\frac{t}{Q_{\mathrm{t}}}=\frac{1}{k_{2} Q_{\mathrm{e}, \mathrm{c}}^{2}}+\frac{t}{Q_{\mathrm{e}, \mathrm{c}}}$

where $Q_{e}$ is the amount of $\mathrm{Cu}$ (II) ions adsorbed by a unit mass of adsorbent at equilibrium $(\mathrm{mg} / \mathrm{g}) ; Q_{e, c}$ is the calculated amount of $\mathrm{Cu}(\mathrm{II})$ ions adsorbed by a unit mass of adsorbent at equilibrium $(\mathrm{mg} / \mathrm{g}) ; Q_{\mathrm{t}}$ is the adsorption capacity at any time $\mathrm{t}(\mathrm{mg} / \mathrm{g}) ; k_{1}$ is the pseudo-first order rate constant $\left(\mathrm{min}^{-1}\right) ; k_{2}$ is the pseudosecond order rate constant $\left(\mathrm{g} \mathrm{min}^{-1} \mathrm{mg}^{-1}\right)$.

Weber and Morris intraparticle diffusion model is often used to determine if intraparticle diffusion is the rate limiting step, as described by Eq. (6):

$Q_{\mathrm{t}}=k_{\mathrm{i}} t^{1 / 2}+\mathrm{C}$

where $k_{\mathrm{i}}$ is the intraparticle diffusion rate constant $\left(\mathrm{mg} \mathrm{g}^{-1} \mathrm{~min}^{-1 / 2}\right.$ ) and $C$ is constant reflecting the boundary layer effect, and larger intercepts suggest that the surface sorption has greater contribution in the rate limiting step.

\subsection{Selectivity and anti-interference test of the G-HQ-C IIPS}

Selective adsorption experiment of G-HQ-C IIPs/NIPs was studied at room temperature at $\mathrm{pH}=6.0$. During the adsorption process, $10 \mathrm{mg}$ G-HQ-C IIPs/NIPs were added into $10 \mathrm{~mL}$ solution containing $\mathrm{Cu}(\mathrm{II}), \mathrm{Cd}(\mathrm{II}), \mathrm{Pb}(\mathrm{II}), \mathrm{Zn}(\mathrm{II}), \mathrm{Co}(\mathrm{II}), \mathrm{Mg}(\mathrm{II}), \mathrm{Mn}$ (II) and $\mathrm{Ni}$ (II) ions at equal initial concentrations $(20 \mathrm{mg} / \mathrm{L})$. The selectivity of G-HQ-C IIPs and NIPs were obtained from following Eqs. (7)-(9):

Distribution coefficient, $K_{\mathrm{M}^{2+}}=\frac{Q_{\mathrm{e}}}{C_{\mathrm{e}}}$

Selectivity coefficient, $\beta_{\mathrm{Cu}^{2+} / \mathrm{M}^{2+}}=\frac{K_{\mathrm{Cu}^{2+}}}{K_{\mathrm{M}^{2+}}}$

Relative selectivity coefficient, $k^{\prime}=\frac{\beta_{\mathrm{IIP}}}{\beta_{\mathrm{NIP}}}$

where $K_{\mathrm{Cu}^{2+}}$ and $K_{\mathrm{M}^{2+}}$ are the distribution coefficient of $\mathrm{Cu}$ (II) and other heavy metal ions; $Q_{e}$ is the amount of metal ions adsorbed by a unit mass of adsorbent of adsorbent at equilibrium $(\mathrm{mg} / \mathrm{g})$; $\mathrm{C}_{\mathrm{e}}$ is the concentration of $\mathrm{Cu}(\mathrm{II})$ ions at equilibrium $(\mathrm{mg} / \mathrm{L})$.

Furthermore, the adsorption capacity of G-HQ-C IIPs/NIPs were compared by adding $10 \mathrm{mg}$ G-HQ-C IIPs/NIPs into a series of $10 \mathrm{~mL}$ $5 \mathrm{mg} / \mathrm{L} \mathrm{Cu}(\mathrm{II})$ solution in the presence of $50 \mathrm{mg} / \mathrm{L}$ interferential ions, including $\mathrm{Cd}^{2+}, \mathrm{Pb}^{2+}, \mathrm{Mn}^{2+}, \mathrm{Mg}^{2+}, \mathrm{Fe}^{2+}, \mathrm{Co}^{2+}, \mathrm{Zn}^{2+}, \mathrm{Ca}^{2+}, \mathrm{Ni}^{2+}$, $\mathrm{Na}^{+}$and $\mathrm{K}^{+}$.

\subsection{Reusability study of the G-HQ-C IIPs}

The used G-HQ-C IIPs after adsorption of $\mathrm{Cu}(\mathrm{II})$ ions were immersed into $0.1 \mathrm{~mol} / \mathrm{L} \mathrm{HAc}$ solution for about ten times (per $30 \mathrm{~min}$ ) to ensure the complete removal of the adsorbed $\mathrm{Cu}(\mathrm{II})$ ions at room temperature $\left(25^{\circ} \mathrm{C}\right)$. Then, the G-HQ-C IIPs was neutralized by $\mathrm{NaOH}$ solution and dried in a vacuum oven for next adsorption. Subsequently, the regenerated G-HQ-C IIPs were added into $10 \mathrm{~mL}$ of $5 \mathrm{mg} / \mathrm{L} \mathrm{Cu}(\mathrm{II})$ solution at $25^{\circ} \mathrm{C}$, and then were shaken for $24 \mathrm{~h}$ for the re-adsorption of $\mathrm{Cu}(\mathrm{II})$ ions to investigate the reusability.

\subsection{Application of the G-HQ-C IIPs to removal of Cu(II) from real water samples}

Removal experiments of $\mathrm{Cu}(\mathrm{II})$ were carried out in round bottom centrifugal tubes by adding $10 \mathrm{mg}$ dried G-HQ-C IIPs into $10 \mathrm{~mL}$ real water samples (river, lake and sea water) just simply filtered, and then shaken for $24 \mathrm{~h}$ with a vapour-bathing vibrator at room temperature $\left(25^{\circ} \mathrm{C}\right)$ and $\mathrm{pH}=6.0$. The concentration of $\mathrm{Cu}$ (II) ion was determined by ICP-MS. The standard addition method was used since trace amounts of $\mathrm{Cu}(\mathrm{II})$ ions were present in the three real water samples. All the adsorption experiments were performed in triplicate. 


\section{Results and discussion}

\subsection{Preparation and characterizations of G-HQ-C IIPS}

G-HQ-C IIPs were prepared by a simple chemical cross-linking among the three monomers including gelatin $(G)$, 8-hydroxyquinoline (HQ) and chitosan (C), as illustrated in Fig. 1. As seen, triple helixes $\mathrm{G}$ would change to single chain after heating (about $60^{\circ} \mathrm{C}$ ) to reduce the steric hindrance among G, HQ and C. Moreover, the formation of G-HQ through Mannich reaction (Fig. S1) between $\mathrm{HQ}$ and the terminal $-\mathrm{NH}_{2}$ of $\mathrm{G}$ would well solve the tricky problem that HQ is insoluble in water, and it is critical for the further chemical cross-linking in aqueous phase. Subsequently, complexes were obtained via chelation among G-HQ C and $\mathrm{Cu}(\mathrm{II})$ ions, and then G-HQ-C@Cu was formed after chemical cross-linking. Finally, high selective recognition cavities in G-HQ$\mathrm{C}$ IIPs were generated by removal of $\mathrm{Cu}(\mathrm{II})$ ions. Herein, the criterion for selection of raw materials (G, HQ and C) and synthesis process in non-toxic water, ethanol and acetic acid as solvents is according to green chemistry principle, to use non/less dangerous chemicals and to reduce/eliminate waste discharge.

In the synthesis process of green multi-funcional monomer based G-HQ-C IIPs, the amounts of G, HQ, C and $\mathrm{Cu}$ (II) ions should be optimized, as described in Experimental S1. As can be seen from Figs. S2-4, the highest adsorption capacity was attained from the optimal mass ratio of $\mathrm{G}: \mathrm{HQ}=2: 1, \mathrm{G}-\mathrm{HQ}: \mathrm{C}: \mathrm{Cu}(\mathrm{II})=150: 150: 5$. Therefore, $150 \mathrm{mg} \mathrm{G}-\mathrm{HQ}, 150 \mathrm{mg} \mathrm{C}$ and $5 \mathrm{mg} \mathrm{Cu}$ (II) ions were utilized to prepare G-HQ-C IIPs/NIPs for further studies. In addition, as listed in Table S1, G-HQ-C IIPs had much higher adsorption capacities than that of single $\mathrm{G}$ or $\mathrm{C}$, indicating the hybrid process could improve the adsorption performance of single material.

FT-IR spectra of G, HQ and G-HQ (Fig. 2a) can reveal successful reaction between $\mathrm{G}$ and $\mathrm{HQ}$. As seen, G-HQ displayed a broad band at about $3355 \mathrm{~cm}^{-1}$ corresponding to the stretching vibration of $\mathrm{N}-\mathrm{H}$ and $\mathrm{O}-\mathrm{H}$, as well as the combined absorption peak of $\mathrm{N}-\mathrm{H}$ bending and $\mathrm{C}-\mathrm{N}$ stretching vibration at $1635 \mathrm{~cm}^{-1}$ indicated the amide I band from $\mathrm{G}$, and meanwhile, the benzene ring skeleton vibration at $1574 / 1504 \mathrm{~cm}^{-1}$ and $\mathrm{C}-\mathrm{H}$ bending vibration at $1462 \mathrm{~cm}^{-1}$ suggested the phenyl/pyridine hydroxyl group from the HQ [40,41]. Characteristic peaks observed at 1273 and $1157 \mathrm{~cm}^{-1}$ were possibly due to the asymmetric and symmetrical stretching vibrations of etheroxy groups $(\mathrm{C}-\mathrm{O}-\mathrm{C})$ in ester groups, while peak at $1115 \mathrm{~cm}^{-1}$ quite resulted from the stretching vibration of C-O. Fig. 2b shows the FT-IR spectra of G-HQ, NIPs, IIPs and G-HQ-C@Cu. As seen, the broad band at about $3355 \mathrm{~cm}^{-1}$ corresponding to the stretching vibration of $\mathrm{N}-\mathrm{H}$ and $\mathrm{O}-\mathrm{H}$ shifted to higher wavenumber, peak at $1635 \mathrm{~cm}^{-1}$ shifted to $1639 \mathrm{~cm}^{-1}$ and peak at $1115 \mathrm{~cm}^{-1}$ corresponding to stretching vibration of $\mathrm{C}-\mathrm{O}$ shifted to lower wavenumber of $1072 \mathrm{~cm}^{-1}$ after G-HQ reaction with $\mathrm{C}$ to form NIPs [33]. Moreover, the band at about $3355 \mathrm{~cm}^{-1}$ shifted to much higher wavenumber with lower peak intensity and the intensity of peaks at 1639, 1574, 1504, 1462, $1273,1153,1072 \mathrm{~cm}^{-1}$ reduced after G-HQ-C IIPs combining with copper, indicating the G-HQ-C IIPs' abundant reactive sites such as amino, amide, hydroxyl, quinoline and carboxyl groups to combine with $\mathrm{Cu}(\mathrm{II})$ [14]. The above results revealed that imprinted cavities were formed in the G-HQ-C IIPs, which could be used to selectively adsorb $\mathrm{Cu}(\mathrm{II})$ ions.

Hence, the FT-IR spectra indicated that three kinds interactions towards $\mathrm{Cu}$ (II) would take effect. One is the larger binding ability of HQ chelating towards $\mathrm{Cu}(\mathrm{II})$ ions. Another is the cooperation effect of amide from $\mathrm{G}$ and $\mathrm{C}$, forming the high stability amide - $\mathrm{Cu}(\mathrm{II})$ complex. In addition, the hydroxyl and carboxyl in amino acid residuals from $\mathrm{G}$ also participate in the chelation of $\mathrm{Cu}(\mathrm{II})$ ions. Therefore, the recognition of $\mathrm{Cu}$ (II) by G-HQ-C IIPs would be
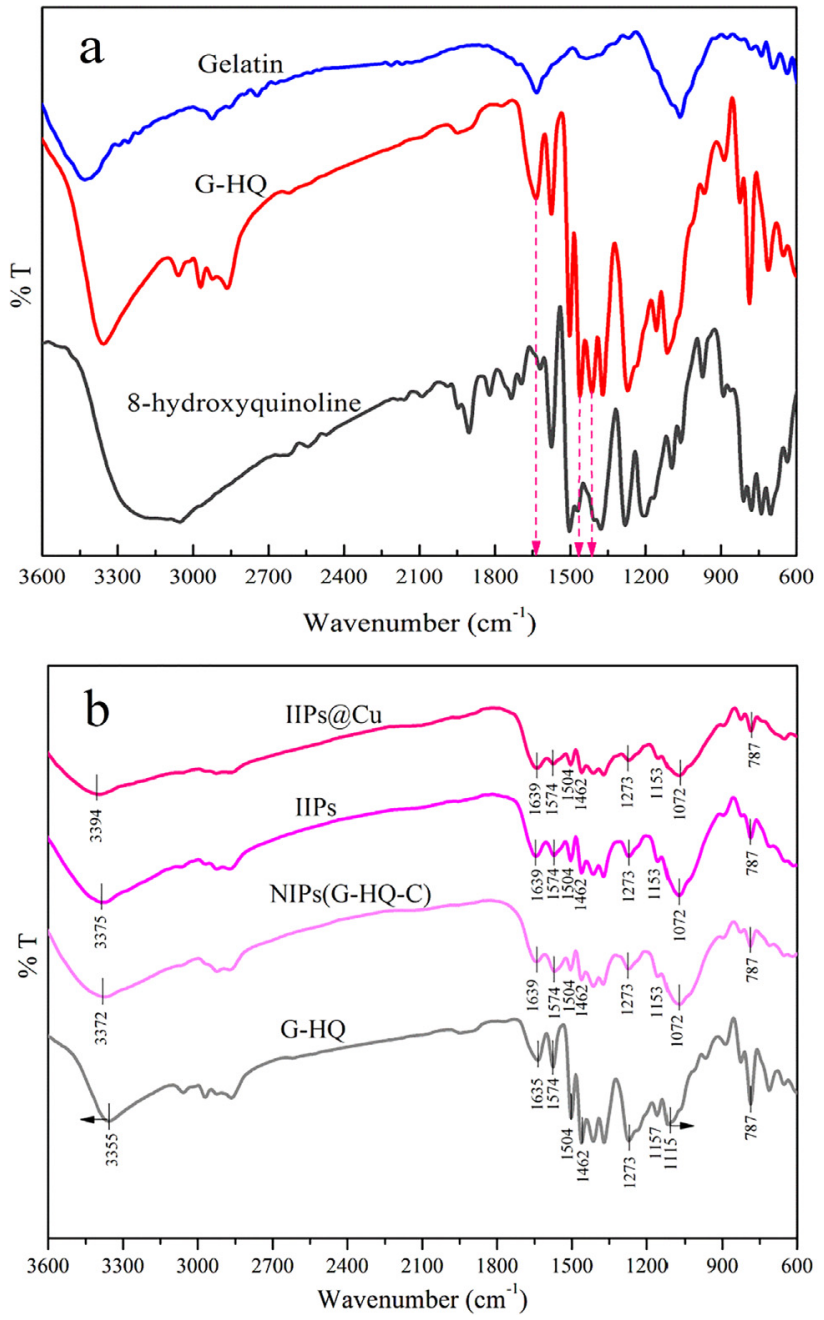

Fig. 2. FTIR spectra of (a) gelatin (G), 8-hydroxyquinoline (HQ), G-HQ and (b) G-HQC IIPs/NIPS.

enhanced by multi-point interactions from the three functional monomers complementary to each other.

Fig. 3 shows the morphologies of G-HQ-C IIPs/NIPs. It could be clearly seen that IIPs membrane had pore structure about 5$15 \mu \mathrm{m}$ (a, b); however, the NIPs formed a uniform membrane without obvious pores (c, d). Besides, the G-HQ-C IIPs provided significantly larger specific surface areas $\left(120.91 \mathrm{~m}^{2} / \mathrm{g}\right)$ than that of NIPs $\left(7.40 \mathrm{~m}^{2} / \mathrm{g}\right)$, as listed in Table $\mathrm{S} 2$, which was beneficial for the $\mathrm{Cu}(\mathrm{II})$ adsorption. Consequently, the rough surface of G-HQ-C IIPs would provide much more contact area compared with the smooth surface of NIPs, meaning remarkably higher adsorption capacity of IIPs.

\subsection{Adsorption capacity of $\mathrm{Cu}(\mathrm{II})$ ions on G-HQ-C IIPS}

In general, adsorption capacities of $\mathrm{Cu}(\mathrm{II})$ ions on G-HQ-C IIPs were dependent on sample solution $\mathrm{pH}$, initial $\mathrm{Cu}(\mathrm{II})$ concentration, contact time and temperature. Detailed investigations were carried out as follows.

\subsubsection{Effect of $\mathrm{pH}$ on adsorption capacity of Cu(II) ions on G-HQ-C IIPS}

The effect of initial $\mathrm{pH}$ of sample solution on adsorption capacity was firstly studied because most chelation reactions were $\mathrm{pH}$ sensitive. As shown in Fig. S5, the adsorption capacity increased 

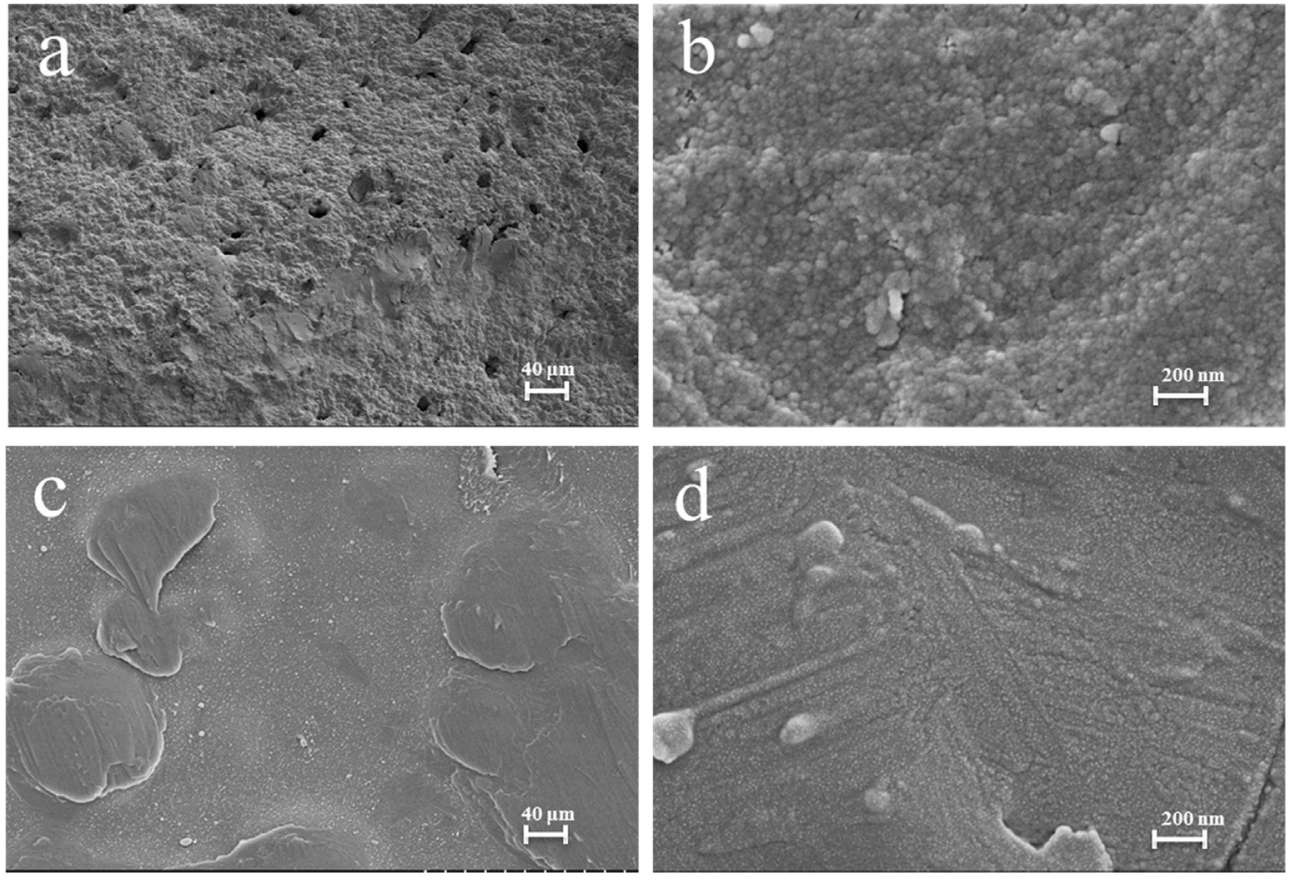

Fig. 3. SEM images of G-HQ-C IIPs (a, b) and NIPs (c, d).

obviously as $\mathrm{pH}$ of the initial solution increased from 2.0 to 6.0, while decreased after 6.0. To explain this phenomenon, the zeta potential distribution of G-HQ-C IIPs was investigated, as shown in Fig. S6. As seen from the figure, the point of zero charge of GHQ-C IIPs was corresponding to $\mathrm{pH}$ 6.0. When the $\mathrm{pH}$ was lower than 6.0, the net charge of G-HQ-C IIPs was positive, the increasing electrostatic repulsion between the positively charged IIPs and $\mathrm{Cu}$ (II) ions would lead to the continuous reduction of the adsorption capacities towards $\mathrm{Cu}(\mathrm{II})$ ions. Especially, the lowest adsorption capacity at $\mathrm{pH} 2.0$ very likely resulted from the electric repulsion between protonated amino groups of IIPs and the positively charged $\mathrm{Cu}$ (II) ions, reducing the chelating ability of amino groups towards $\mathrm{Cu}(\mathrm{II})$ ions. When the $\mathrm{pH}$ was higher than 6.0, the net charge of G-HQ-C IIPs was negative (Fig. S6); however, under the $\mathrm{pH}$ condition, $\mathrm{Cu}(\mathrm{II})$ ions generally could be easily transformed to $\mathrm{Cu}(\mathrm{OH})_{2}$ or precipitates [42], leading to sudden decrease in adsorption capacity (Fig. S5). Therefore, pH 5.0-6.0 was the appropriate $\mathrm{pH}$ range to adsorb $\mathrm{Cu}(\mathrm{II})$ ions from aqueous solution, and $\mathrm{pH} 6.0$ was selected for the following experiments.

\subsubsection{Adsorption isotherms of G-HQ-C IIPs}

Saturated adsorption experiments were performed in order to evaluate the adsorption capacities of G-HQ-C IIPs and NIPs at concentrations from 5 to $500 \mathrm{mg} / \mathrm{L}$ from aqueous solutions at $\mathrm{pH}=6.0$ with temperatures of 298,308 and $318 \mathrm{~K}$, respectively. As shown in Fig. 4 , the adsorption capacity $\left(Q_{e}\right)$ increased with the increase of initial concentrations of $\mathrm{Cu}(\mathrm{II})$ ions and temperature. In addition, $Q_{e}$ of IIPs continued to rise even when the initial concentration exceeded $500 \mathrm{mg} / \mathrm{L}$, while the growth of $Q_{e}$ of NIPs slowed down. The insert figures are digital photos of IIPs samples after saturated adsorption with the initial concentrations from 5 to $500 \mathrm{mg} / \mathrm{L}$ at $298 \mathrm{~K}$. As can be seen by naked eyes, adsorbents after adsorption became greener with the increase of concentration, though it is well known that the $\mathrm{Cu}(\mathrm{II})$ solution of 5 to $500 \mathrm{mg} / \mathrm{L}$ is almost colourless. So, it intuitively indicated that G-HQ-C IIPs was an effective adsorbent towards $\mathrm{Cu}(\mathrm{II})$ ions in aqueous solution.

To further evaluate the maximum adsorption capacity of G-HQC IIPs/NIPs and make out the possible adsorption mechanism, data

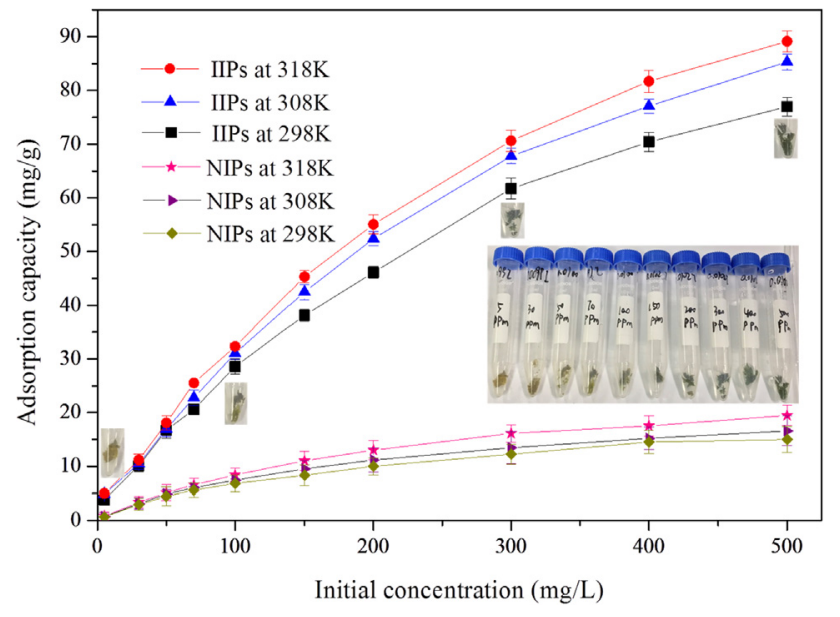

Fig. 4. Adsorption isotherms of G-HQ-C IIPs/NIPs towards $\mathrm{Cu}(\mathrm{II})$ at different initial concentrations and the insert figures are digital photos of IIPs samples after saturated adsorption. ( $\mathrm{pH}=6.0,10 \mathrm{mg}$ adsorbents, $10 \mathrm{~mL}$ ).

fitted with Langmuir and Freundlich models were given in Table 1 and plots were shown in Figs. S7 and S8, respectively. The Langmuir isotherm model fitted the adsorption data better with all the correlation coefficients of $\mathrm{R}^{2}>0.999$, which were higher than that of Freundlich isotherm model at the three temperatures, indicating that the adsorption of $\mathrm{Cu}(\mathrm{II})$ ions was monolayer adsorption processes on G-HQ-C IIPs and NIPs. Moreover, as the the temperature increasing from 25 to $45{ }^{\circ} \mathrm{C}$, the maximum adsorption capacities of IIPs towards $\mathrm{Cu}$ (II) increased from 111.81 to $163.05 \mathrm{mg} / \mathrm{g}$ along with the imprinting factors rising from 5.33 to 5.95 , which may well be attributed to the increased temperature benefiting the internal diffusion of $\mathrm{Cu}$ (II) ions. In view of ambient temperature, $25^{\circ} \mathrm{C}$ was preferred in the practical applications. Excitedly, at room temperature, the presented maximum adsorption capacity by G-HQ-C IIPs ( $111.81 \mathrm{mg} / \mathrm{g}$ ) is much higher than that of most of the reported adsorbents for $\mathrm{Cu}(\mathrm{II})$ removal $[8,20,24,43-48]$. 
Table 1

Parameters of Langmuir and Freundlich adsorption isotherm models for adsorption of $\mathrm{Cu}(\mathrm{II})$ ions.

\begin{tabular}{|c|c|c|c|c|c|c|c|c|}
\hline \multirow[t]{2}{*}{ Temperature } & \multirow[t]{2}{*}{ Polymers } & \multirow[t]{2}{*}{ Imprinting Factor } & \multicolumn{3}{|c|}{ Langmuir model } & \multicolumn{3}{|c|}{ Freundlich model } \\
\hline & & & $Q_{\max }(\mathrm{mg} / \mathrm{g})$ & $K_{\mathrm{L}}(\mathrm{L} / \mathrm{mg})$ & $R^{2}$ & $\overline{K_{\mathrm{F}}}$ & $n$ & $R^{2}$ \\
\hline \multirow[t]{2}{*}{$298 \mathrm{~K}$} & IIPs & 5.33 & 111.81 & 1.73 & 0.9998 & 1.71 & 1.54 & 0.9778 \\
\hline & NIPs & & 20.99 & 9.23 & 0.9921 & 0.50 & 1.77 & 0.9857 \\
\hline \multirow[t]{2}{*}{$308 \mathrm{~K}$} & IIPs & 5.88 & 131.93 & 1.67 & 0.9995 & 1.59 & 1.47 & 0.9832 \\
\hline & NIPs & & 22.41 & 8.23 & 0.9963 & 0.55 & 1.78 & 0.9839 \\
\hline \multirow[t]{2}{*}{$318 \mathrm{~K}$} & IIPs & 5.95 & 163.05 & 1.61 & 0.9997 & 1.70 & 1.47 & 0.9832 \\
\hline & NIPs & & 27.38 & 7.45 & 0.9987 & 0.52 & 1.66 & 0.9829 \\
\hline
\end{tabular}

\subsubsection{Adsorption kinetics of G-HQ-C IIPS}

Dynamic adsorption experiments were carried out to investigate the effect of contact time on the adsorption of $\mathrm{Cu}(\mathrm{II})$ on G-HQ-C IIPs and NIPs of different initial concentrations (5, 30 and $100 \mathrm{ppm}$ ) at $298 \mathrm{~K}$, so as to evaluate the ionic transfer properties of G-HQ-C IIPs and NIPs. As shown in Fig. 5, the changes of adsorption capacities of G-HQ-C IIPs and NIPs at different initial concentrations were consistent, and the adsorption capacities of G-HQ-C IIPs at equilibrium were much higher than that of NIPs. Adsorption capacities of $\mathrm{Cu}(\mathrm{II})$ on G-HQ-C IIPs increased rapidly with the increase of time in the first $180 \mathrm{~min}$, then the increasement rate gradually decreased and adsorption capacities approached to equilibrium. As for G-HQ-C NIPs, adsorption capacities approached to equilibrium after $60 \mathrm{~min}$ but with much lower values. Rapid adsorption of initial time may result from the abundant active sites on the surface of materials, indicating that there was much higher affinity between $\mathrm{Cu}(\mathrm{II})$ and G-HQ-C IIPs than NIPs. In addition, the adsorption capacities increased with the increasing initial $\mathrm{Cu}(\mathrm{II})$ concentration may be due to the increase of mole number of $\mathrm{Cu}$ (II) available to materials' surface at a higher concentration, resulting in the increase of collisions from $\mathrm{Cu}(\mathrm{II})$ ions and the improvement of driving force to overcome mass transfer resistances between the aqueous solution and solid phases [50].

Furthermore, dynamic adsorption data simulated with the pseudo-first-order equation and pseudo-second-order kinetics equations were shown in Fig. 6a-d and the corresponding kinetic parameters were listed in Table S3. All the adsorption capacities $\left(Q_{e}\right)$ obtained at saturated adsorption experiments of IIPs and NIPs were very close with the calculated adsorption capacities $\left(Q_{e, c}\right)$ from pseudo-second-order kinetic model. Besides, the linear regression $R^{2}$ value of IIPs and NIPs were all above 0.999 in the pseudo-second-order kinetic model, much higher than that in the pseudo-first-order kinetic model. These results suggested that

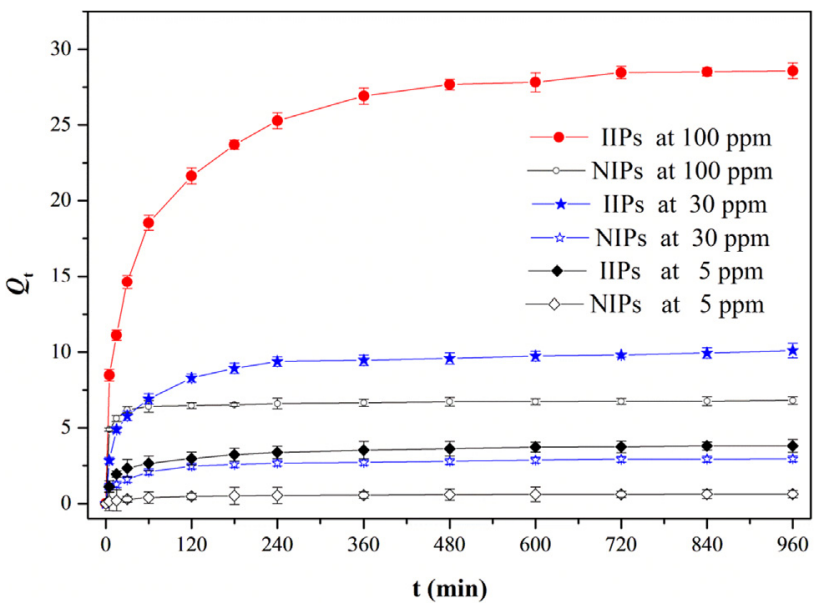

Fig. 5. Effect of time on $\mathrm{Cu}(\mathrm{II})$ ion adsorption. ( $\mathrm{pH}=6.0,10 \mathrm{mg}$ adsorbents, $10 \mathrm{~mL}$, $298 \mathrm{~K})$. the pseudo-second-order kinetic model fitted better to the $\mathrm{Cu}(\mathrm{II})$ adsorption data than the pseudo-first-order kinetic model so as to describe the adsorption kinetics for $\mathrm{Cu}(\mathrm{II})$ adsorption on GHQ-C IIPs and NIPs. In addition, the lower rate constants $\left(k_{2}\right)$ of IIPs in the pseudo-second-order kinetic model were agree with the slower achievement of adsorption equilibrium of IIPs at the same $\mathrm{Cu}(\mathrm{II})$ initial concentration compared with NIPs. The rate constants $\left(k_{2}\right)$ of IIPs and NIPs decreased with the increase of $\mathrm{Cu}(\mathrm{II})$ initial concentration, which were consistent with the experimental results that the adsorption equilibrium of higher concentration would took longer time. According to the assumptions of the pesudo-second-order kinetic model, the rate controlling step of $\mathrm{Cu}(\mathrm{II})$ adsorption behavior was chemisorption which involved valence forces through sharing or exchange of electrons between $\mathrm{Cu}(\mathrm{II})$ and G-HQ-C IIPs/NIPs [51].

It is essential to confirm the steps involved in the adsorption of $\mathrm{Cu}(\mathrm{II})$ on G-HQ-C IIPs and NIPs. The solute transfer was usually characterized by intraparticle diffusion in a solid-liquid adsorption process, so Weber and Morris intraparticle diffusion model was used to fitting dynamic adsorption data, as shown in Fig. 6e and f. The plots of $Q_{t}$ versus $t^{1 / 2}$ for $\mathrm{Cu}(\mathrm{II})$ adsorption on both IIPs and NIPs included three-section linearity, indicating three consecutive steps taking place during the adsorption process: (1) Fast transport of the $\mathrm{Cu}$ (II) from bulk solution through liquid film to the adsorbent exterior surface of G-HQ-C IIPs. (2) Gradual diffusion of $\mathrm{Cu}$ (II) into the intraparticles or pores of G-HQ-C IIPs or NIPs except for a small quantity of sorption on the external surface. Besides, this step was rate limiting, in which the slope was defined as the intraparticle diffusion rate constant $\left(k_{\mathrm{i}}\right)$ and the larger intercept suggested the greater contribution of surface adsorption in the rate limiting step. (3) Final equilibrium stage of adsorption and desorption of $\mathrm{Cu}(\mathrm{II})$ on G-HQ-C IIPs or NIPs solute on the interior surfaces of the pores and capillary spaces of the adsorbent [52]. In addition, all the linear lines did not pass through the origin, indicating that intraparticle diffusion was not the only rate limiting step and there were other adsorption stages affecting the adsorption process [53] of $\mathrm{Cu}(\mathrm{II})$ on G-HQ-C IIPs or NIPs.

\subsection{Selectivity and anti-interference ability of G-HQ-C IIPS}

In real application, competitive adsorption of other ions would directly influence the $\mathrm{Cu}(\mathrm{II})$ removal efficiency by competing for the available adsorption sites, so selectivity and anti-interference ability took primary concerns to estimate adsorbents performances. The distribution and selectivity coefficient were chosen to evaluate the selectivity of G-HQ-C IIPs/NIPs at the same initial concentration. As seen in Table S4, IIPs provided higher adsorption capacities towards $\mathrm{Cu}(\mathrm{II})$ ions than that towards the other common divalent ions such as $\mathrm{Cd}(\mathrm{II}), \mathrm{Pb}(\mathrm{II}), \mathrm{Zn}(\mathrm{II}), \mathrm{Co}(\mathrm{II}), \mathrm{Mg}(\mathrm{II}), \mathrm{Mn}(\mathrm{II})$ and $\mathrm{Ni}(\mathrm{II})$ ions. The selectivity coefficients of the IIPs for $\mathrm{Cu}(\mathrm{II})$ ions with respect to the foreign species were higher than 18.71. Additionally, the distribution and selectivity coefficient of IIPs for $\mathrm{Cu}(\mathrm{II})$ ions were considerably higher than that of NIPs. Relative selectivity coefficients $\left(k^{\prime}\right)$ were above 7.5 even as high as 85.1 , indicating very 

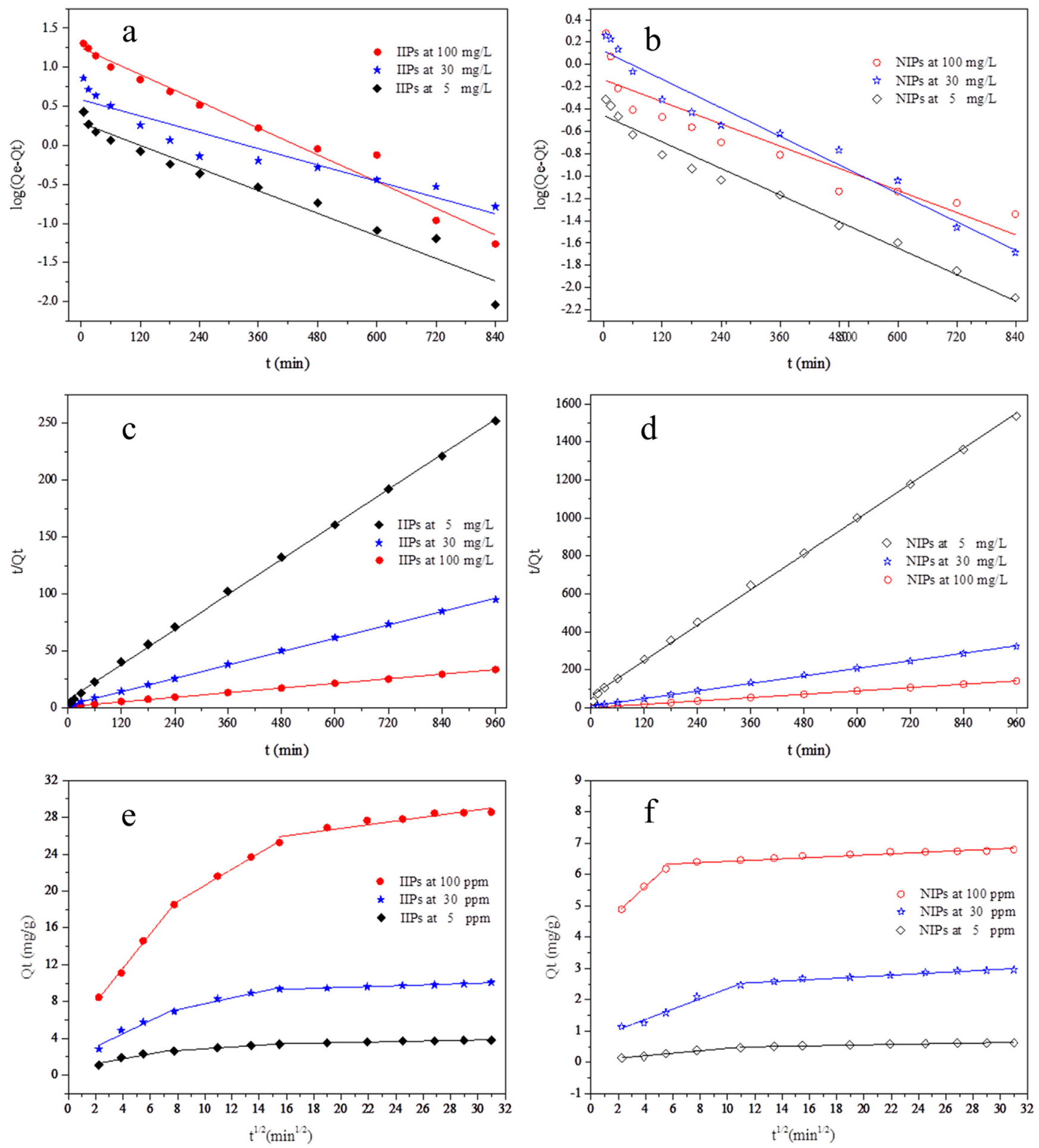

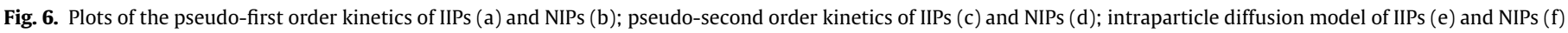
at the initial $\mathrm{Cu}(\mathrm{II})$ concentration of 5,30 and $100 \mathrm{mg} / \mathrm{L} .(\mathrm{pH}=6.0,10 \mathrm{mg}$ adsorbents, $10 \mathrm{~mL}, 298 \mathrm{~K})$.

high affinity and selectivity of the IIPs towards $\mathrm{Cu}(\mathrm{II})$ ions compared to NIPs. Therefore, the prepared G-HQ-C IIPs had an excellent selectivity for $\mathrm{Cu}$ (II) ions.

To further evaluate the anti-interference ability of the IIPs for $\mathrm{Cu}(\mathrm{II})$, the adsorption capacity of $\mathrm{Cu}(\mathrm{II})$ ions were examined in the mixture solutions containing $\mathrm{Cu}(\mathrm{II})$ ions and possible interfering ions, including $\mathrm{Cd}^{2+}, \mathrm{Pb}^{2+}, \mathrm{Mn}^{2+}, \mathrm{Mg}^{2+}, \mathrm{Fe}^{3+}, \mathrm{Co}^{2+}, \mathrm{Zn}^{2+}, \mathrm{Ca}^{2+}$,
$\mathrm{Ni}^{2+}, \mathrm{Na}^{+}$and $\mathrm{K}^{+}$, with interfering ion concentrations 10 times the $\mathrm{Cu}$ (II) ions. As shown in Fig. 7, those co-existing ions did not cause significant reduction in the adsorption capacity of $\mathrm{Cu}(\mathrm{II})$ ions, indicating interfering ions will not compete for the active adsorption sites with $\mathrm{Cu}(\mathrm{II})$. All the results demonstrated that G-HQ-C IIPs possessed strong anti-interference ability and they could highly selectively and reliably remove $\mathrm{Cu}(\mathrm{II})$ ions. 


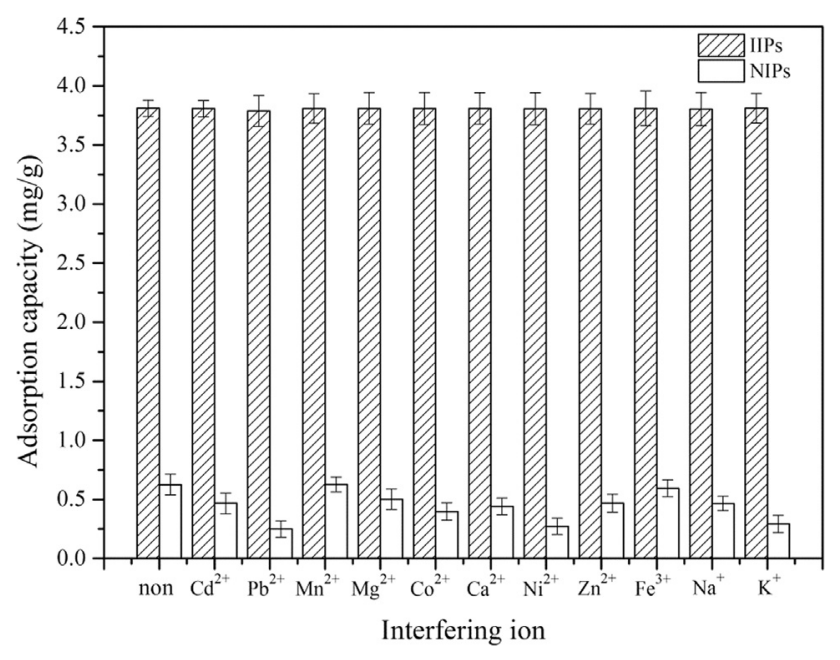

Fig. 7. Adsorption capacities for target template ions in the presence of interferential ions, including $\mathrm{Cd}^{2+}, \mathrm{Pb}^{2+}, \mathrm{Mn}^{2+}, \mathrm{Mg}^{2+}, \mathrm{Fe}^{3+}, \mathrm{Co}^{2+}, \mathrm{Zn}^{2+}, \mathrm{Ca}^{2+}, \mathrm{Na}^{+}$and $\mathrm{K}^{+}$, respectively. ( $\mathrm{pH}=6.0 ; 10 \mathrm{mg}$ adsorbents; $10 \mathrm{~mL} ; 298 \mathrm{~K} ; 5 \mathrm{mg} / \mathrm{L} \mathrm{Cu(II)}$ ions concentration and $50 \mathrm{mg} / \mathrm{L}$ interfering ions concentration, respectively).

\subsection{Reusability of G-HQ-C IIPS}

Reusability of adsorbents is an important factor to evaluate their potentially economic values in practical applications. Herein, $0.1 \mathrm{~mol} / \mathrm{L}$ HAc solution was used as desorption medium to regenerate G-HQ-C IIPs. Fig. 8 shows the resorption efficiency of G-HQ-C IIPs for $\mathrm{Cu}(\mathrm{II})$ by ten adsorption-desorption cycles of regeneration. As seen, the resorption efficiency decreased gradually with the increasing regeneration cycles, but the re-adsorption efficiency was still kept higher than $90 \%$ after ten cycles of reuse, indicating that the G-HQ-C IIPs could effectively remove $\mathrm{Cu}(\mathrm{II})$ in at least ten recycles. In addition, as shown in Fig. S9, the morphology of IIPs with five cycle didn't have significant difference from that of the initial IIPs, while the IIPs after ten times cycling just had slight decrease of surface roughness and slight damage of pores, which could suggest the IIPs had good mechanical behavior and were physically/chemically stable. Therefore, the G-HQ-C IIPs owning remarkable regeneration performance could be ideal adsorbent candidates for $\mathrm{Cu}(\mathrm{II})$ removal from aqueous solutions.

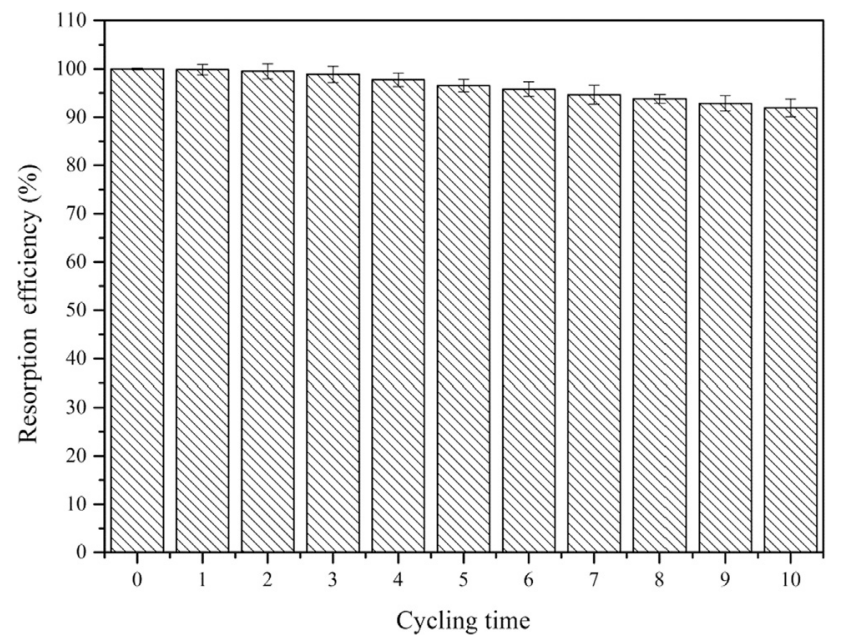

Fig. 8. Resorption efficiency of G-HQ-C IIPs. ( $\mathrm{pH}=6.0 ; 10 \mathrm{mg}$ adsorbents, $10 \mathrm{~mL}$, $5 \mathrm{mg} / \mathrm{L}$ initial concentration, $298 \mathrm{~K}$ ).

\subsection{Removal of $\mathrm{Cu}(\mathrm{II})$ from real water samples and method performance comparison}

The feasibility of the application of G-HQ-C IIPs for removing $\mathrm{Cu}$ (II) ions from real water samples (river, lake and sea water) was evaluated by comparing the concentration of $\mathrm{Cu}(\mathrm{II})$ before and after adsorption by $10 \mathrm{mg}$ IIPs. The endogenous concentrations of $\mathrm{Cu}(\mathrm{II})$ ions in lake, sea and river water were quite low $(0.014$, 0.052 and $0.087 \mathrm{mg} / \mathrm{L}$, respectively), so the standard addition method was used for the removal experiments. As listed in Table 2, the concentrations of $\mathrm{Cu}(\mathrm{II})$ ions were dramatically reduced to much lower than the allowable $\mathrm{Cu}(\mathrm{II})$ in drinking water of $1.3 \mathrm{mg} / \mathrm{L}$. For an example, in sea water, even the high concentration of $10 \mathrm{mg} / \mathrm{L} \mathrm{Cu}(\mathrm{II})$ was found to reduce down to only $0.65 \mathrm{mg} / \mathrm{L}$ after G-HQ-C IIPs adsorption, and the removal efficiency was high up to 93.5\%. Therefore, the G-HQ-C IIPs were highly feasible for $\mathrm{Cu}(\mathrm{II})$ adsorptive-removal and thereby water-quality purification.

Adsorption performance of G-HQ-C IIPs towards $\mathrm{Cu}(\mathrm{II})$ ions was compared especially in the maximum adsorption capacity and selectivity coefficient with other reported adsorbents, as summarized in Table S5 $[8,20,24,43-49,54]$. As can be seen from the table, the values of adsorption capacity and selectivity coefficients for our G-HQ-C IIPs are comparable or higher than most previously reported Cu-IIPs, except that fabricated on the surface of graphene oxide(GO) [49] and multiwalled carbon nanotubes (MWCNTs) [54]. However, it should be noted that adsorption performance depended on the adsorbent components and structure. For example, graphene oxide (GO) [49] and MWCNTs [54] owning super large specific surface area directly result in larger contact areas of adsorbents toward $\mathrm{Cu}$ (II) ions. In other words, the adsorption capacity of G-HQ-C IIPs can be further improved by introducing nanomaterial as carriers. More importantly, low cost and ecofriendly functional monomers and solvent (water and ethanol) are utilize in G-HQ-C IIPs preparation, which is superior to the above mentioned IIPs, considering they all use more or less toxic organic reagents. Therefore, on the whole, our developed G-HQ-C IIPs possessed high adsorption capacity and selectivity, as well as remarkable advantages such as low-cost and eco-friendliness.

\subsection{Adsorption properties of other metal ion templating IIPs based on G-HQ-C}

Considering multi-point interactions from multiple functional monomers, it would have the possibility to produce a series of tailor-made heavy metal ion imprinted polymers. Therefore, G-HQ-C based $\mathrm{Cd}(\mathrm{II}), \mathrm{Hg}(\mathrm{II})$ and $\mathrm{Pb}(\mathrm{II})$ imprinted polymers were prepared as the above same procedure, excepting the replacement of templates $\mathrm{Cu}(\mathrm{II})$ by $\mathrm{Cd}(\mathrm{II}), \mathrm{Hg}(\mathrm{II})$ and $\mathrm{Pb}(\mathrm{II})$, respectively. Saturated adsorption experiments were carried out by adding $10 \mathrm{mg}$ IIPs/NIPs into $10 \mathrm{~mL}$ target metal ion solutions. As seen from

Table 2

Removal of $\mathrm{Cu}(\mathrm{II})$ from real water samples by G-HQ-C IIPs.

\begin{tabular}{llll}
\hline Sample & $\begin{array}{l}\text { Added } \\
(\mathrm{mg} / \mathrm{L})\end{array}$ & $\begin{array}{l}\text { Before adsorption } \\
(\mathrm{mg} / \mathrm{L})\end{array}$ & $\begin{array}{l}\text { After adsorption } \\
(\mathrm{mg} / \mathrm{L})\end{array}$ \\
\hline Lake water & 0 & $0.01432 \pm 0.01^{\mathrm{a}}$ & $0.01141 \pm 0.00$ \\
& 5 & $5.014 \pm 0.15$ & $0.08014 \pm 0.02$ \\
Sea water & 10 & $10.01 \pm 0.21$ & $0.4542 \pm 0.06$ \\
& 0 & $0.05210 \pm 0.02$ & $0.04625 \pm 0.01$ \\
River water & 5 & $5.052 \pm 0.14$ & $0.1246 \pm 0.06$ \\
& 10 & $10.05 \pm 0.19$ & $0.6473 \pm 0.08$ \\
& 5 & $0.08721 \pm 0.01$ & $0.03611 \pm 0.01$ \\
& 10 & $5.087 \pm 0.17$ & $0.1016 \pm 0.03$ \\
& $10.09 \pm 0.23$ & $0.2015 \pm 0.05$ \\
\hline
\end{tabular}

${ }^{\text {a }}$ Average value of three determinations \pm standard deviation $(n=3)$. 


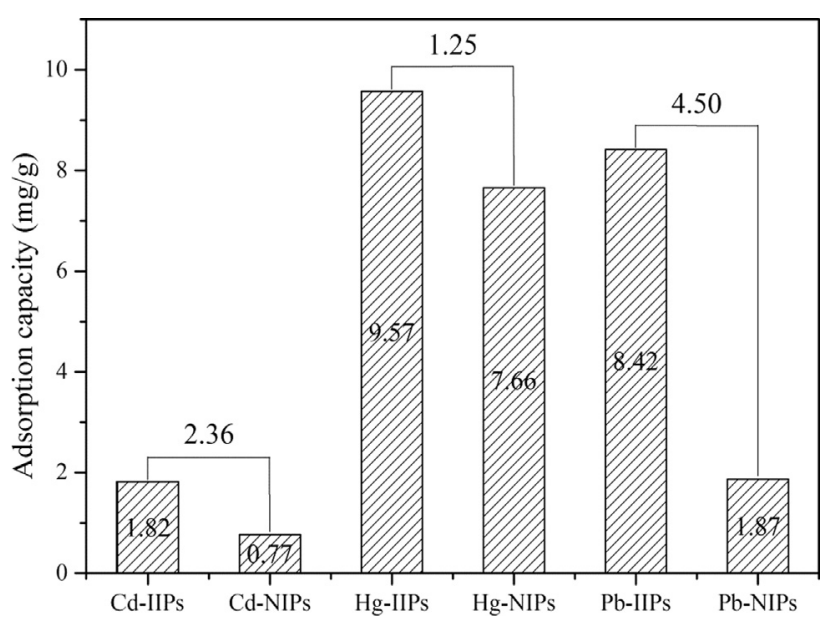

Fig. 9. Adsorption capacity and imprinting factor of $\mathrm{G}-\mathrm{HQ}-\mathrm{C} \mathrm{Cd} / \mathrm{Hg} / \mathrm{Pb}$ IIPs and their respective NIPs for corresponding template ions of $\mathrm{Cd}(\mathrm{II}), \mathrm{Hg}(\mathrm{II})$ and $\mathrm{Pb}(\mathrm{II})$. (10 mg adsorbents, $10 \mathrm{~mL}, 10 \mathrm{mg} / \mathrm{L}$ initial concentration, $298 \mathrm{~K}$, without adjusting the $\mathrm{pH}$ ).

Fig. 9, Cd IIPs and Pb IIPs attained high imprinting factors of 2.36 and 4.50 , respectively, presenting excellent imprinting effect. So, the two IIPs could selectively adsorb corresponding template Cd (II) and $\mathrm{Pb}(\mathrm{II})$, respectively. Although the imprinting factor was not very high (1.25) of $\mathrm{Hg}$ IIPs, it was still above 1 and the adsorption capacity was high, which could indicate the Hg IIPs were suitable for selective adsorption of $\mathrm{Hg}(\mathrm{II})$. Therefore, the fabrication of G-HQ-C IIPs using three functional monomers could be developed into a general imprinting strategy towards various heavy metal ions through multi-point interactions, which would have important significance in enriching the research connotations of IIPs/MIPs and expand related applications.

\section{Conclusions}

In conclusion, new green multi-functional monomers based G-HQ-C IIPs were prepared by a simple chemical cross-linking method using G, HQ and $C$ as functional monomers with ethanol and water as solvents. The G-HQ-C IIPs could effectively adsorb $\mathrm{Cu}$ (II) ions from aqueous solution with the maximum adsorption capacity of $111.81 \mathrm{mg} / \mathrm{g}$ at room temperature, and demonstrate excellent selectivity to remove $\mathrm{Cu}(\mathrm{II})$ ions over co-existing competitive heavy metal ions. Moreover, green synthesis strategy and low cost made G-HQ-C IIPs an ideal adsorbent to the selective and efficient removal of $\mathrm{Cu}(\mathrm{II})$ ions from aqueous solutions and it could offer a general ion imprinting strategy towards heavy metal ions. In view of the advantages, further explorations on devising and synthesizing green multi-functional monomers will provide promising perspectives for specific removal of targeted heavy metals with high effectiveness and satisfy green sustainable development requirements.

\section{Acknowledgements}

This work was financially supported by the National Natural Science Foundation of China (21876199, 21575159, 41776110), the Natural Science Foundation of Shandong Province of China (ZR2016BL25), the Department of Science and Technology of Shandong Province of China (GG201709290055, 2017ZH093), the National Research Foundation of Korea supported this work (2017M3D1A1039287, 2018M3A7B4071203).

The authors have declared no conflict of interest.

\section{Appendix A. Supplementary material}

Supplementary data to this article can be found online at https://doi.org/10.1016/j.jcis.2019.01.081.

\section{References}

[1] N.N. Dil, M. Sadeghi, Free radical synthesis of nanosilver/gelatin-poly (acrylic acid) nanocomposite hydrogels employed for antibacterial activity and removal of $\mathrm{Cu}(\mathrm{II})$ metal ions, J. Hazard. Mater. 351 (2018) 38-53.

[2] J. Qi, B.W. Li, X.R. Wang, Z. Zhang, Z. Wang, L.X. Chen, Three-dimensional paper-based micro-fluidic chip device for multiplexed fluorescence detection of $\mathrm{Cu}^{2+}$ and $\mathrm{Hg}^{2+}$ ions based on ion imprinting technology, Sens. Actuat. B 251 (2017) 224-233.

[3] J.H. Chen, Q.L. Liu, S.R. Hua, J.C. Ni, Y.S. He, Adsorption mechanism of Cu(II) ions from aqueous solution by glutaraldehyde crosslinked humic acid-immobilized sodium alginate porous membrane adsorbent, Chem. Eng. J. 173 (2011) 511 519.

[4] F.J. Alguacil, M. Alonso, F.A. Lopez, A. Lopez-Delgado, Pseudo-emulsion membrane strip dispersion (PEMSD) pertraction of chromium(VI) using CYPHOS IL101 ionic liquid as carrier, Environ. Sci. Technol. 44 (2010) 75047508.

[5] M.A. Barakat, New trends in removing heavy metals from industrial wastewater, Arab. J. Chem. 4 (2011) 361-377.

[6] D. Setyono, S. Valiyaveettil, Functionalized paper-a readily accessible adsorbent for removal of dissolved heavy metal salts and nanoparticles from water, J. Hazard. Mater. 302 (2016) 120-128.

[7] Y.L. Niu, K. Li, D.W. Ying, Y.L. Wang, J.P. Jia, Novel recyclable adsorbent for the removal of copper(II) and lead(II) from aqueous solution, Bioresource Technol. 229 (2017) 63-68.

[8] Z.Q. Ren, X.Y. Zhu, J. Du, D.L. Kong, N. Wang, Z. Wang, Q. Wang, W. Liu, Q.S. Li, Z. Y. Zhou, Facile and green preparation of novel adsorption materials by combining sol-gel with ion imprinting technology for selective removal of $\mathrm{Cu}$ (II) ions from aqueous solution, Appl. Surf. Sci. 435 (2018) 574-584.

[9] A.L. Ahmad, S. Sumathi, B.H. Hameed, Residual oil and suspended solid removal using natural adsorbents chitosan, bentonite and activated carbon: a comparative study, Chem. Eng. J. 108 (2005) 179-185.

[10] X.B. Luo, C.C. Wang, S.L. Luo, R.Z. Dong, X.M. Tu, G.S. Zeng, Adsorption of As (III) and As (V) from water using magnetite $\mathrm{Fe}_{3} \mathrm{O}_{4}$-reduced graphite oxide- $\mathrm{MnO}_{2}$ nanocomposites, Chem. Eng. J. 187 (2012) 45-52.

[11] T.B. Musso, M.E. Parolo, G. Pettinari, F.M. Francisca, Cu(II) and Zn(II) adsorption capacity of three different clay liner materials, J. Environ. Manage. 146 (2014) $50-58$.

[12] M. Mushtaq, H.N. Bhatti, M. Iqbal, S. Noreen, Eriobotrya japonica seed biocomposite efficiency for copper adsorption: isotherms, kinetics, thermodynamic and desorption studies, J. Environ. Manage. 176 (2016) 21-33.

[13] S. Kagaya, H. Miyazaki, Y. Inoue, T. Kato, H. Yanai, W. Kamichatani, T. Kajiwara, M. Saito, K. Tohda, Chelating fibers prepared with a wet spinning technique using a mixture of a viscose solution and a polymer ligand for the separation of metal ions in an aqueous solution, J. Hazard. Mater. 203-204 (2012) 370-373.

[14] J. Liu, D.H. Su, J.R. Yao, Y.F. Huang, Z.Z. Shao, X. Chen, Soy protein-based polyethylenimine hydrogel and its high selectivity for copper ions removal in wastewater treatment, J. Mater. Chem. A 5 (2017) 4163-4171.

[15] J.Q. Fu, L.X. Chen, J.H. Li, Z. Zhang, Current status and challenges of ion imprinting, J. Mater. Chem. A 3 (2015) 13598-13627.

[16] K. Huang, B.B. Li, F. Zhou, S.R. Mei, Y.K. Zhou, T. Jing, Selective solid-phase extraction of lead ions in water samples using three-dimensional ionimprinted polymers, Anal. Chem. 88 (2016) 6820-6826.

[17] S.F. Xu, L.X. Chen, J.H. Li, Y.F. Guan, H.Z. Lu, Novel $\mathrm{Hg}^{2+}$-imprinted polymers based on thymine- $\mathrm{Hg}^{2+}$-thymine interaction for highly selective preconcentration of $\mathrm{Hg}^{2+}$ in water samples, J. Hazard. Mater. 237-238 (2012) 347-354

[18] Z. Zhang, J.H. Li, X.L. Song, J.P. Ma, L.X. Chen, $\mathrm{Hg}^{2+}$ ion-imprinted polymers sorbents based on dithizone- $\mathrm{Hg}^{2+}$ chelation for mercury speciation analysis in environmental and biological samples, RSC Adv. 4 (2014) 46444-46453.

[19] X.Q. Cai, J.H. Li, Z. Zhang, F.F. Yang, R.C. Dong, L.X. Chen, Novel $\mathrm{Pb}^{2+}$ ion imprinted polymers based on ionic interaction via synergy of dual functional monomers for selective solid-phase extraction of $\mathrm{Pb}^{2+}$ in water samples, ACS Appl. Mater. Interfaces 6 (2014) 305-313.

[20] C.C. Kang, W.M. Li, L. Tan, H. Li, C.H. Wei, Y.W. Tang, Highly ordered metal ion imprinted mesoporous silica particles exhibiting specific recognition and fast adsorption Kinetic, J. Mater. Chem. A 1 (2013) 7147-7153.

[21] R. He, W.M. Li, D.Y. Deng, W.S. Chen, H. Li, C.H. Wei, Y.W. Tang, Efficient removal of lead from highly acidic wastewater by periodic ion imprinted mesoporous SBA-15 organosilica combining metal coordination and cocondensation, J. Mater. Chem. A 3 (2015) 9789-9798.

[22] R. He, Z.H. Wang, L. Tan, Y. Zhong, W.M. Li, D. Xing, C.H. Wei, Y.W. Tang, Design and fabrication of highly ordered ion imprinted SBA-15 and MCM-41 mesoporous organosilicas for efficient removal of $\mathrm{Ni}^{2+}$ from different properties of wastewaters, Micropor. and Mesopor. Mat. 257 (2018) 212-221.

[23] A. Afkhami, T. Madrakian, M. Soltani-Shahrivar, M. Ahmadi, H. Ghaedi, Selective and sensitive electrochemical determination of trace amounts of mercury ion in some real samples using an ion imprinted polymer nanomodifier, J. Electrochem. Soc. 163 (2016) 68-75. 
[24] L.X. Chen, X.Y. Wang, W.H. Lu, X.Q. Wu, J.H. Li, Molecular imprinting: perspectives and applications, Chem. Soc. Rev. 45 (2016) 2137-2211.

[25] A. Speltini, A. Scalabrini, F. Maraschi, M. Sturini, A. Profumo, Newest applications of molecularly imprinted polymers for extraction of contaminants from environmental and food matrices: a review, Anal. Chim. Acta 974 (2017) 1-26.

[26] X. Li, X.G. Ma, R.F. Huang, X.W. Xie, L.H. Guo, M.Y. Zhang, Synthesis of a molecularly imprinted polymer on $\mathrm{mSiO}_{2} @ \mathrm{Fe}_{3} \mathrm{O}_{4}$ for the selective adsorption of atrazine, J. Sep. Sci. 41 (2018) 2837-2845.

[27] X.W. Xie, X.G. Ma, L.H. Guo, Y.M. Fan, G.L. Zeng, M.Y. Zhang, J. Li, Novel magnetic multi-templates molecularly imprinted polymer for selective and rapid removal and detection of alkylphenols in water, Chem. Eng. J. 357 (2019) $56-65$.

[28] L.X. Chen, S.F. Xu, J.H. Li, Recent advances in molecular imprinting technology: current status, challenges and highlighted applications, Chem. Soc. Rev. 40 (2011) 2922-2942.

[29] N.T. Hoai, D. Yoo, D. Kim, Batch and column separation characteristics of copper-imprinted porous polymer micro-beads synthesized by a direct imprinting method, J. Hazard. Mater. 173 (2010) 462-467.

[30] M. Haruki, Y. Konnai, A. Shimada, H. Takeuchi, Molecularly imprinted polymer-assisted refolding of lysozyme, Biotechnol. Progr. 23 (2007) 1254 1257.

[31] M. Zhang, R. Helleur, Y. Zhang, Ion-imprinted chitosan gel beads for selective adsorption of $\mathrm{Ag}^{+}$from aqueous solutions, Carbohyd. Polym. 130 (2015) 206212.

[32] H.T. Xing J.H Chen, X Sun, Y.H. Huang Z B. Su, S.R. Hu, W Weng S.X. Li, H.X Guo, W.B. Wu, Y.S. He, F.M. Li, Y. Huang, $\mathrm{NH}_{2}$-rich polymer/graphene oxide use as a novel adsorbent for removal of $\mathrm{Cu}(\mathrm{II})$ from aqueous solution, Chem. Eng. J. 263 (2015) 280-289.

[33] S.S.D. Elanchezhiyan, S.M. Prabhu, S. Meenaksh, Effective adsorption of oil droplets from oil-in-water emulsion using metal ions encapsulated biopolymers: Role of metal ions and their mechanism in oil removal, Int. J. Biol. Macromol. 112 (2018) 294-305.

[34] Y.O. Wong, P. Miranda, E. Rosenberg, Metal coordination and selectivity with oxine ligands bound to silica polyamine composites, J. Appl. Polym. Sci. 115 (2010) 2855-2864.

[35] J. Tan, H.F. Wang, X.P. Yan, A fluorescent sensor array based on ion imprinted mesoporous silica, Biosens. Bioelectron. 24 (2009) 3316-3321.

[36] H. Li, X. Gao, Y. Wang, X. Zhang, Z. Tong, Comparison of chitosan/starch composite film properties before and after cross-linking, Int. J. Biol. Macromol. 52 (2013) 275-279.

[37] H. Ghasemzadeh, F. Ghanaat, Antimicrobial alginate/PVA silver nanocomposite hydrogel, synthesis and characterization, J. Polym. Res. 21 (2014) 355-369.

[38] P. Kampalanonwat, P. Supaphol, Preparation and adsorption behavior of aminated electrospun polyacrylonitrile nanofiber mats for heavy metal ion removal, ACS Appl. Mater. Interfaces 2 (2010) 3619-3627.

[39] S.M. Alshehri, A. Aldalbahi, A.B. Al-hajji, A.A. Chaudhary, M. Panhuisc, N. Alhokbany, T. Ahamad, Development of carboxymethyl cellulose-based hydrogel and nanosilver composite as antimicrobial agents for UTI pathogens, Carbohydr. Polym. 138 (2016) 229-236.

[40] C.R. Lan, M.H. Yang, Synthesis, properties and applications of silicaimmobilized 8-quinolinol, Anal. Chim. Acta 287 (1994) 101-109.

[41] I.M. Nagpure, M.M. Duvenhage, S.S. Pitale, O.M. Ntwaeaborwa, J.J. Terblans, H. C. Swart, Synthesis, thermal and spectroscopic characterization of $\mathrm{Caq}_{2}$ (Calcium 8-Hydroxyquinoline) organic phosphor, J. Fluoresc. 22 (2012) 1271-1279.

[42] I.A.H. Schneider, J. Rubio, Sorption of heavy metal ions by the nonliving biomass of freshwater macrophytes, Environ. Sci. Technol. 33 (1999) 2213-2217.

[43] Y.M. Ren, M.L. Zhang, D. Zhao, Synthesis and properties of magnetic Cu(II) ionimprinted composite adsorbent for selective removal of copper, Desalination 228 (2008) 135-149.

[44] G.H. Wu, G.C. Song, D.Y. Wu, Y.Y. Shen, Z.Q. Wang, C.Y. He, Synthesis of ionimprinted mesoporous silica gel sorbent for selective adsorption of copper ions in aqueous media, Microchim. Acta 171 (2010) 203-209.

[45] M. Roushani, S. Abbasi, H. Khani, Synthesis and application of ion-imprinted polymer nanoparticles for the extraction and preconcentration of copper ions in environmental water samples, Environ. Monit. Assess. 187 (2015) 601-610.

[46] W. Peng, Z.Z. Xie, G. Cheng, L. Shi, Y.B. Zhang, Amino-functionalized adsorbent prepared by means of $\mathrm{Cu}(\mathrm{II})$ imprinted method and its selective removal of copper from aqueous solutions, J. Hazard. Mater. 294 (2015) 9-16.

[47] Y. Zhu, Z.S. Bai, W.Q. Luo, B.J. Wang, L.L. Zhai, A facile ion imprinted synthesis of selective biosorbent for $\mathrm{Cu}^{2+}$ via microfluidic technology, J. Chem. Technol. Biotechnol. 92 (2017) 2009-2022.

48] J.X. Duan, X Li, C.C. Zhang, The synthesis and adsorption performance of polyamine $\mathrm{Cu}^{2+}$ imprinted polymer for selective removal of $\mathrm{Cu}^{2+}$, Polym. Bull. 74 (2017) 3487-3504.

[49] D.L. Kong, N. Qiao, H. Liu, J. Du, N. Wang, Z.Y. Zhou, Z.Q. Ren, Fast and efficient removal of copper using sandwich-like graphene oxide composite imprinted materials, Chem. Eng. J. 326 (2017) 141-150.

[50] W.H. Lu, J.H. Li, Y.Q. Sheng, X.S. Zhang, J.M. You, L.X. Chen, One-pot synthesis of magnetic iron oxide nanoparticle-multiwalled carbon nanotube composites for enhanced removal of $\mathrm{Cr}(\mathrm{VI})$ from aqueous solution, J. Colloid Interf. Sci. 505 (2017) 1134-1146.

51] Y. Pang, G.M. Zeng, L. Tang, Y. Zhang, Y.Y. Liu, X.X. Lei, Z. Li, J.C. Zhang, G.X. Xie, PEI-grafted magnetic porous powder for highly effective adsorption of heavy metal ions, Desalination 281 (2011) 278-284.

[52] L. Jiang, Y. Liu, S. Liu, X. Hu, G. Zeng, X. Hu, S. Liu, S. Liu, B. Huang, M. Li, Fabrication of b-cyclodextrin/poly (l-glutamic acid) supported magnetic graphene oxide and its adsorption behavior for 17b-estradiol, Chem. Eng. J. 308 (2017) 597-605.

[53] H.K. Boparai, M. Joseph, D.M. O'Carroll, Kinetics and thermodynamics of cadmium ion removal by adsorption onto nano zerovalent iron particles, J. Hazard. Mater. 186 (2011) 458-465

[54] K. Turan, R.S. Canlıdinc, O.M. Kalfa, Selective preconcentration of trace amounts of $\mathrm{Cu}(\mathrm{II})$ with surface-imprinted multiwalled carbon nanotubes, Clean Soil Air Water 46 (2018) 1700580-1700589. 